\title{
Male Attitudes Towards Children, Fatherhood, and Childrearing: A Descriptive Profile from South African Social Attitudes Survey (SASAS)
}

\author{
Anderson J. Franklin", ${ }^{*}$, Monde Makiwane ${ }^{2}$ and Tawanda Makusha ${ }^{2}$ \\ ${ }^{I}$ Boston College, Campion 309, 140 Commonwealth Ave, Chestnut Hill, MA 02467, USA \\ ${ }^{2}$ Human Sciences Research Council, Pretoria, South Africa, Nelson Mandela Metropolitan University, Port Elizabeth, \\ South Africa
}

\begin{abstract}
South African male attitudes towards children, fatherhood and childrearing remain an important topic for research and policy development given concerns about men's engagement with children and the family. This study utilizes a subsample of males from the national South African Social Attitudes Survey to profile attitudes of males cross analyzed by survey designated racial groups. Results show that males in general, have a positive attitude towards having children and feel that they are not a burden. A greater number of Black African males than the other racial groups believe children are a financial burden and restrict employment choices. Most males believe that men want to have a loving relationship with children and perform best as fathers if married to the mother. The majority of them believe that it is a crisis in the country that many fathers do not co-reside with their children. Consistent across racial groups, most males are split about discipline with half believing in spanking, and that it teaches children right from wrong. Most males believe that it is better to talk to children than spank them. In examining responses to survey questions, Black African males trended away from the prevalent attitudes more than Colored, Asian Indian, and White males. Family service providers can utilize these attitudes of men in planning intervention programs and policy development.
\end{abstract}

Keywords: Childrearing attitudes, disciplining, fatherhood, financial burden, racial groups, South African men.

\section{INTRODUCTION}

There is a major need to study South African male attitudes towards children, fatherhood and childrearing given the paucity of research with men in this area. It is consistent with the growing research endeavors over past decades that have highlighted the need for further information on men as fathers in South Africa [1]. Major factors in the efforts to understand contemporary status of fathering in South Africa are migration patterns of men from rural to urban areas, along with the legacy of labor practices that disrupted men co-residing with their children $[2,3]$. There is the debate about masculinity and fatherhood, absent fathers, the importance of fathers co-residing with children, in contrast to males serving as social fathers in child development [4]. The perspective of fatherhood as a social construction, more than solely defined in terms of its biological connection and required co-residency but the nurturing role played bynonresidential fathers, other male kin, or male surrogates in the community, adds to the South African discourse [2].

These perspectives on the status of men, and men as fathers represent the search for a more multidimensional understanding of fatherhood [5]. There are important views related to men, men as fathers and fatherhood. Multiple questions for research open for exploration because of this

*Address correspondence to this author at the Boston College, Lynch School of Education, Campion 309, 140 Commonwealth Ave, Chestnut Hill, MA 02467, USA; Tel: (617) 522-4572; Fax: (617) 522-1981;

E-mail: aj.franklin@bc.edu body of scholarly work. It elucidates the discourse on men, men as fathers, and their views related to childrearing.

The study reported in this paper, is another effort to further research on men and men as fathers through analyzing male's responses in a survey. Inadequate sampling, design, or lack of appropriately targeted questions in many surveys in South Africa, complicates the full comprehension of the role of men as fathers, their engagement in the family, or their views about childrearing [5]. This research is a descriptive study utilizing responses to specific questions in the 2012, South African Social Attitudes Survey (SASAS) developed to learn of South African's attitudes towards children, childrearing, fatherhood and discipline. It further examines the data by racial groups as designated by the survey: Black African, "Colored", Indian/Asian and White. The objective is to learn if there are any specific population differences in attitudes that would warrant attention from researchers, practitioners and policy makers.

In their seminal book, Baba: Men and Fatherhood in South Africa, Richter, et al. identified their main aim as pursuing the impact of Apartheid in affecting fathers and fatherhood in South Africa. Indeed, in their work, they concluded that race in conjunction with class shaped

\footnotetext{
${ }^{1}$ The terms used for racial classification were those used in the original South African Social Attitude Survey. Their use in this paper does not refer to preference of the authors. The authors are aware of the contentious nature of the continued use of racial classification and racial lexis. This is especially the case when referred to the term "Coloured" where some authors have preferred to use an alternative term of "Mixed Race".
} 
fatherhood in South Africa [6]. Gordon, et al. noted stark differences in racial groups when it came to intergenerational issues [7]. For instance they noted that, "Black South Africans were found to be more engaged in forms of kinship support networks when compared to other population groups". They further noted that, "Population group differences in intergenerational family consensus were also found with Indian South Africans reporting higher levels of perceived consensus [between generations] on all issues compared with Whites, Colored and Black South Africans".

Thus, other family researchers have confirmed the racial differences on family matters initially suggested by Richter, et al. [6]. In line with these findings, this study examines racial differences specifically on the perspectives of fatherhood. While there might be other factors that influence fatherhood perspectives, like class, this preliminary fatherhood study confines itself to representing racial differences in attitudes by South African men related to children, childrearing, fatherhood and discipline.

\section{Absent Father Perspective}

Attitudes of men towards children, childrearing, fatherhood and discipline connect to their presence in the home, connection to their children, and engagement in family matters. It is reasonable to assume that absence of fathers in the home might reflect in males' views about these elements of father-child connection. The decline in the engagement of men in their traditional family roles has led the government to develop family strengthening policies [6]. Expectations about the role of men in families have undergone global transformations in contemporary times creating strain upon traditional paternal functions and necessity for the development of policy to increase father ties to family with greater participation in child caring and co-parenting [1].

The absence of fathers in the home has been linked to high male mortality, male labour migration, and births that occur outside stable relationships [1, 8]. In turn, family instability by no fathers in the home and rising single female heads of households have been related to poor academic performance and educational advancement of children and youth [8]. Educators, family specialists, and government policy makers considered this as a continuous trend, which has been evident for decades, as a threat to the future adult workforce and pool of leaders for South Africa. The development of children in South Africa, as in other countries, relies upon who is in the role of childrearing, and their attitudes towards this responsibility, are paramount to the child's welfare [1,9]. Children constitute a sizable portion of the population.

\section{Children in South Africa}

There are about 18 million children in South Africa making up about $37 \%$ of the population [10]. A vast majority of those children (approximately 84\%) are Black African [11]. A demographic study utilising data from the Statistics South Africa and General Household Survey found that the number of South African children living with both biological parents show a continued decline each year from $38 \%$ in 2002 to $33 \%$ in $2011[10,11]$. However approximately $90 \%$ of children live with co-resident adults, many with their mothers and other relatives which reflects a long trend of care by extended family members. Four percent live with fathers only and when added to the number of children living with both parents, only $36 \%$ of children live with their biological fathers. About $24 \%$ of children do not live with either biological parent. Most Indian/Asian (83\%) and White (74\%) children live with both biological parents in contrast to Black Africans with considerably less children living with both co-resident parents $(27 \%)$. Forty-two percent of Black African children live with their mothers, and likely with other adults, but without the presence of biological fathers [10]. These various arrangements of caretaking for children have implications for understanding men's attitudes towards children, childrearing, fatherhood and discipline. They are complicated by the implications of the population shift from rural Provinces, which relates to the prevalence of absent fathers.

\section{Migration: Implications for Views on Childrearing}

A high proportion of children compared to adults staying in rural Provinces do not co-reside with their fathers. This can be viewed as a product of the migrant labour system's structural legacy. Historically, economic and political policies that impacted family involvement and support shaped fatherhood in South Africa, particularly for Black Africans [1]. Generations of Black African males had to leave the family and migrate great distances to places for work opportunities. Some had contractual annual home visits, which restructured family involvement and the kind of father role men could assume [12, 13]. Migrant fathers in previous generations had expectations about being a part of and providing for their respective families [14]. The intent, as demonstrated by remittances sent home, was manifested by a belief that a good man meant being a good providing father in spite of hardships $[15,16]$. Remittances might be considered a proxy for attitudes towards children, fatherhood, and childrearing.

\section{Remittances}

There is a common perception in South Africa that the traditional role played by men in poor households of being providers for families has been usurped by the government, by providing social assistance in the form of money to the poor households. An analysis of recent data on household income shows that migrants play an essential role in sustaining poor households. The analysis of the National Income Dynamics Data conducted in 2012 showed that the average monthly income of South Africans is R5132. 31 and with a contribution of remittances of R1249, compared to that of social grants of R899. 03. A further analysis shows that poorer areas are more dependent on remittances. This is in spite of the rise in male unemployment in South Africa ${ }^{2}$.

Meeting the challenges of family and raising children remain important when becoming an adult for South African youth [17]. The legacy of migration has cultivated contemporary practices where many men move from rural areas leaving their children behind, and move to the cities for work. This is represented in Fig. (1), which shows that in rural areas, there is a high proportion of children, while cities

\footnotetext{
${ }^{2}$ From the analysis by Monde Makiwane for the National Income Dynamics
} Data, Human Sciences Research Council, Pretoria, South Africa. 


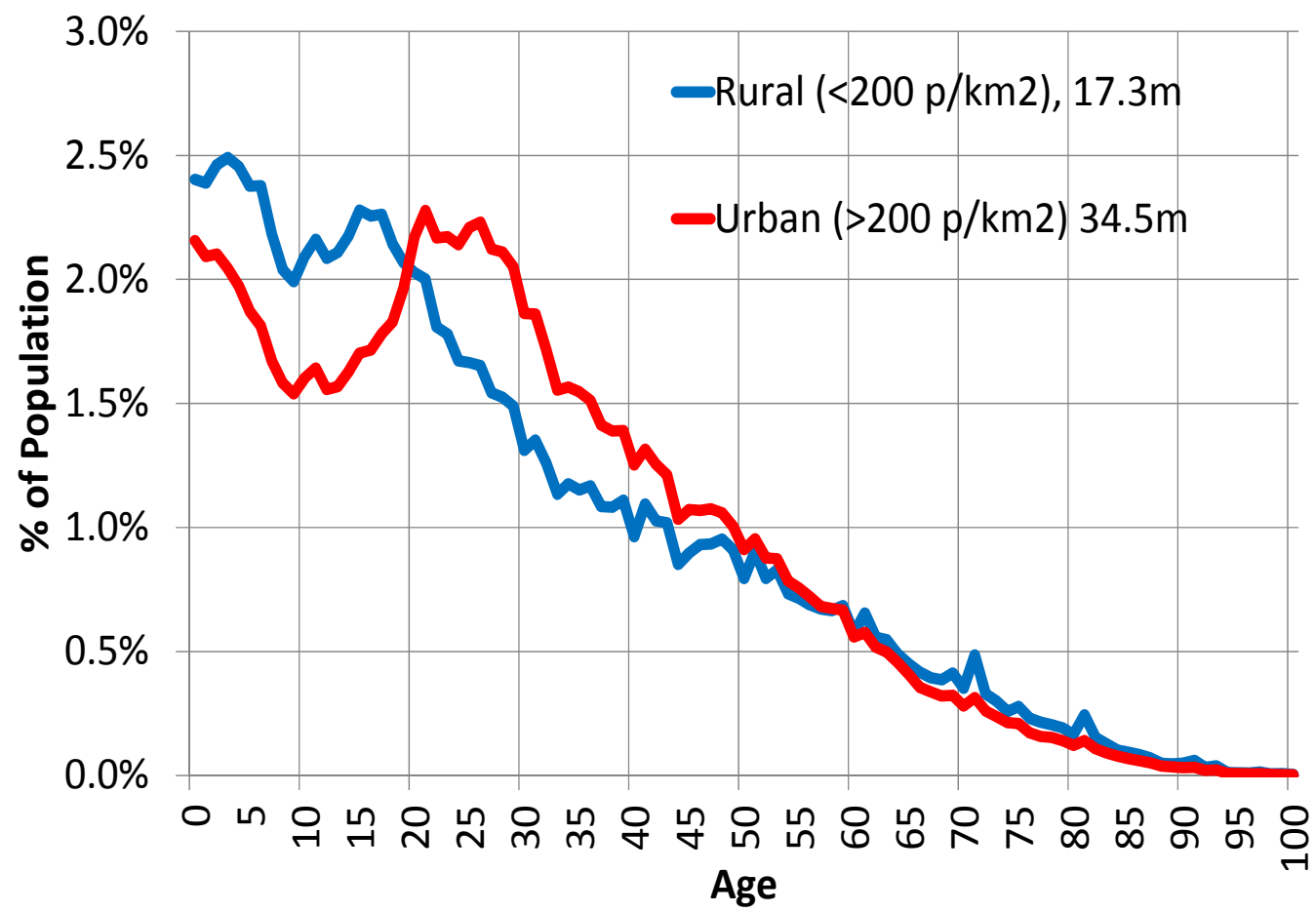

Fig. (1). The Age Distribution: A legacy of Circular Migration in South Africa. Source: Bijker 2013 (Data sourced from the 2011 Census).

are dominated by young adults. Young adults, especially men, move away from the rural areas while leaving their children behind, in order to fulfill their traditional role as breadwinners. This leaves little room for them to assume the "soft" side of fatherhood, that is, as carers of the younger generation.

\section{Father Absence is Not Father Loss: Another Conceptualisation}

Madhavan, et al. cautions against overly interpreting fathers' physical absence into concluding an absolute loss of father-child connections [18]. They advise for a more differentiatied conceptualization that includes the complexity of father support, social connections and the economy. While the broad debate on migration and father's absence has a historical background, the SASAS data reveal that most of the men in South Africa still see themselves as providers of families and see their role as care-givers as little. Thus, while the historical movements of young adults in the past were very much determined by the practice of being required to leave home for work in distant places, contemporary postApartheid migration for work, in South Africa (Fig. 1) is a trend consistent with work patterns of past generations, but motivated by different economic and social reasons [19]. Therefore, given the variations of disengagement of men in co-residency and primary childrearing, attitudes of men towards these responsibilities are important to understand in the total schema of father-child connections.

\section{Poverty Impact Upon Attitudes}

Poverty has a significant impact upon attitudes of men related to providing for family and their capacity to fulfill traditional roles as provider and protector within the family [20]. Moreover, poverty shapes attitudes towards family in relationship to working as well as necessity of education and marketable skills to attain adequate means of employment to provide for families. Cohesiveness of families and communities in past generations offsets the economic impact of poverty by family solidarity and unifying communal values. The growing need for work and the opportunities for work remain a major challenge within South Africa [14]. Those coalescing agents for family attachments with migratory work are less subscribed by contemporary generations of mostly male, and Black South African migrant workers, who have grown up in ruptured families, single parent households with an uncoupling of adult male imperatives for marriage, family and fatherhood. The concept of manhood "ubudoda", a generous manager of the family household, becomes a diminishing ideal [21].

\section{Global Imperatives for the Study of Men, and Men as} Fathers

Parenting today is viewed globally, by professionals and policy makers, as integral to the political, economical, educational, and social well-being of the nation $[1,22]$. The global concern about contemporary patterns of father engagement supports the reason to explore attitudes of South African men. The United Nations Report (2011) on Men in Families, a continuing effort to raise concerns about the tenuous global status of families in contemporary times, profiles the challenges to the structure and function of fathers in the family and its implications for policy by member States [9]. They recognize that fathers play a number of significant roles - companions, care providers, spouses, protectors, models, moral guides, teachers, and breadwinners - whose relative importance varies across generations and sub cultural groups. Only by considering fathers' performance in these various roles, and by taking into account their intersectionality within the socio- 
ecological context, can fathers' impact on child development be evaluated $[23,24]$.

The opportunity to study the attitudes of men towards children, childrearing, fatherhood and discipline with a cross section of South African males as a sub-sample of the total survey population from the South African Social Attitudes Survey (SASAS) might provide some insight into males' attitudes towards children, childrearing, fatherhood and discipline. They constitute $54 \%$ of the total sample or 1,384 males, representing a cross section of racial groups, and provide possibilities for a variety of cross analyses with other demographic and constructed variables that can potentially elucidate other elements of fatherhood and masculinity identity. For this study, initial questions of interest are: 1) What are the attitudes of South African men towards children, childrearing, fatherhood and discipline? 2) Do attitudes of South African men vary by the survey designated racial groups of: Black African, Colored, Asian/Indian, and White? 3) Are there particular trends in the attitudes of South African men that can have implications for fatherhood policy?

\section{METHOD}

\section{Sample}

Data for the study come from the $10^{\text {th }}$ round of the South African Social Attitudes Survey (SASAS), conducted in late 2012 by the Human Sciences Research Council (HSRC). The survey round included a dedicated questionnaire on family structure, family-related roles and values, as well as policy preferences. With financial support from the Department of Science and Technology, the survey was administered to a nationally representative sample of 2,547 respondents aged 16 years and older living in private households. This sample of respondents divided by gender was a sub-sample of $54 \%(n=1,384)$ male respondents, and $46 \%(n=1,163)$ female respondents. Given the percentage of male respondents, we analyzed their responses separately to question on attitudes towards children, childrearing, fatherhood and discipline as an initial means of studying this subsample and furthering knowledge about male perspectives.

\section{SASAS Sample Design}

The Human Sciences Research Council (HSRC) conducts (since 2003) the South African Social Attitudes Survey (SASAS), which is a nationally representative survey series, on an annual basis. The design of the survey yields a representative sample of adults, aged 16 years and older, living in private residences. We used Statistics South Africa's 2001 Population Census enumerator areas (EAs) as primary sampling units (PSUs) and interviewed a total of 2, 547 persons, after which the sample was weighted. The weighted sample represented a total of 35, 669, 776 South Africans who are 16 years or older. The estimated South African population in the year 2011 served as a target population.

\section{Survey Questionnaire}

The 2012 SASAS family questionnaire contained 299 items divided into 12 sections. For this analysis it selected 7 items from the section on Family and Changing Gender
Roles, soliciting views about children, decisions about bringing up children and views about fathers, and 11 items from the section on Views on Children and Parenting, soliciting views about how to raise children and discipline. We analyzed data by the sub-sample of South African men $(54 \%)$ and then by cross analysis by racial populations as designated by the survey: Black Africans (57\%), Colored $(15 \%)$, Indian/Asian (11\%) and White (16\%). We selected items, along with the racial populations, for their centrality to family structure and functioning, the necessity of understanding population differences, and by means of studying male attitudes towards children, childrearing, fatherhood, and discipline.

SASAS was conducted by the Human Sciences Research Council (HSRC). HSRC observes universal ethical principles of research, which include paying special attention to communicating the aims of the study, risks and benefits of participating in a study, and the rights of participants and protecting the validity and integrity of data at every stage of the research. The HSRC Research Ethics Committee for review approved the study proposal, instruments, consent forms and information sheets for this study.

\section{RESULTS}

\section{Attitudes Towards Burden/Pleasures of Children}

Questions from the SASAS that asked about attitudes towards children allowed us to profile how South African males' view the pleasures and burden of having children. To each of the questions, respondents could select one of the following options: strongly agree, agree, neither/nor, disagree, strongly disagree or do not know. The neither/nor, and do not know categories were included in analyses but not reported in these results as they often had few responses. For some items, respondents did not give a response, which accounts for some unequal totals.

Results were that $96 \%[\mathrm{n}=1,331 ; \mathrm{N}=1384]$ of the males agree or strongly agree that: "Watching children growing up is one of life's greatest joys".

\section{Children Interfere with Parents' Freedom}

Sixty-two percent $[62 \%, n=856 ; N=1381]$ of the males disagree or strongly disagree that: "Having children interferes too much with the freedom of the parents". On the other hand $26 \%[n=357 ; N=1381]$ of the males agree or strongly agree that children do interfere with parents' freedom.

Thirty-three percent $[\mathrm{n}=264 ; \mathrm{N}=793]$ of Black African males believe children interfere with parents freedom along with $21 \%[n=44 ; N=207]$ of Colored males, $12 \%[n=19$; $\mathrm{N}=158]$ of Indian/Asian males, and $13 \%[\mathrm{n}=29 ; \mathrm{N}=221]$ of White males.

\section{Financial Burden}

Over half $[59 \%, n=811 ; \mathrm{N}=1381]$ of the males disagree or strongly disagree that: "Children are a financial burden on their parents". However close to one third of the males $28 \%$ $[\mathrm{n}=392 ; \mathrm{N}=1381]$ agree or strongly agree that children are a financial burden. Thirty-eight percent [38\% $[n=299 ; N=793]$ of Black African males agree or strongly agree children are a financial burden, along with $16 \% \quad[n=33 ; N=208]$ of the 
Colored males, $9 \%[\mathrm{n}=14 ; \mathrm{N}=157]$ of the Indian/Asian males and $20 \%[n=45 ; N=221]$ of the White males.

\section{Children Restrict Employment or Career Choices}

Over half $[57 \%, n=780 ; \mathrm{N}=1381]$ of the males disagree or strongly disagree that: "Having children restricts the employment or career choices of one or both parents". On the other hand, over a quarter of the males $[27 \%, n=369$; $\mathrm{N}=1381]$ believe otherwise. Thirty-two percent $[\mathrm{n}=253$; $\mathrm{N}=793$ ] of Black African males agree or strongly agree that children restricts employment or career choices, along with $21 \%[n=44 ; N=208]$ of Colored males, $17 \%[n=26 ; N=157]$ of Indian/Asian males and $20 \%[\mathrm{n}=45 ; \mathrm{N}=221]$ of White males.

\section{Children Increase Social Standing in Society}

The item "having children increases people's social standing in society" in our analysis related to how males perceive the value of children and their potential attachment to them. Over half $[52 \%, n=715 ; \mathrm{N}=1378]$ of the males agree or strongly agree that having children increases people's social standing in society. Over a quarter of the males $[29 \%$, $\mathrm{n}=392 ; \mathrm{N}=1378$ ] disagrees or strongly disagrees with that view. Twenty three percent of the Black African males $[n=179 ; N=791]$ disagrees or strongly disagrees with the view that having children increases people's social standing in society, along with $37 \%[\mathrm{n}=76 ; \mathrm{N}=208]$ of Colored males, $32 \%[n=50 ; 156]$ of Indian/Asian males and $39 \%[n=86$; N221] of White males.

Eighty percent $[n=1,104 ; N=1375]$ of males agree or strongly agree with the view that: "Adult children are an important source of help for elderly parents".

\section{Attitudes Towards Decision-Making in Childrearing}

Male respondents were asked: "Who usually makes/made the decisions about how to bring up your children?" The following results represent the option selected by respondents: $50 \%[\mathrm{n}=522 ; \mathrm{N}=1032]$ of the males indicated that they decide together with their partners; $24 \%[n=245$; $\mathrm{N}=1032]$ indicated mostly me, $12 \%[\mathrm{n}=126]$ indicated mostly by their spouse/ partner, and $10 \%[n=100]$ indicated sometimes by me or sometimes by a spouse or partner.

\section{Attitudes Towards Fathers and Fatherhood}

For each of the items on attitudes towards fathers or fatherhood, respondents could select one of the following options: strongly agree, agree, neither/nor, disagree, strongly disagree or do not know. The neither/nor, and do not know categories were included in analyses but not reported in these results as they often had few responses.

The majority [81\%, $\mathrm{n}=1092 ; \mathrm{N}=1354]$ of the male respondents agrees or strongly agrees that: "It is a crisis that many fathers in South Africa do not live with their children".

A vast majority of respondents [91\%, $n=1246 ; \mathrm{N}=1369]$ agree or strongly agree that: "Most fathers want to have a loving relationship with their children".

Over three quarters of the respondents $78 \%[n=1052$; $\mathrm{N}=1349$ ] agree or strongly agree that: "You get a lot of respect for being a father". Only $10 \%[\mathrm{n}=129 ; \mathrm{N}=1349]$ of male respondents disagree with this view.
Moreover a large majority of respondents $[75 \%, n=1020$; $\mathrm{N}=1366$ ] agree or strongly agree that: "Men perform the best as fathers if they are married to the mothers of their children". Only 14\% [n=186] of male respondents disagree or strongly disagree with this view.

A large majority [ $83 \%, \mathrm{n}=1132 ; \mathrm{N}=1358]$ of males agree or strongly agree that: "A father will feel inadequate if he cannot provide for his family".

Most of the males [71\%, $\mathrm{n}=973 ; \mathrm{N}=1365]$ disagree or strongly disagree that: "Fathers should have less responsibility for child rearing (than mothers)". A portion of the males [ $17 \%, n=227 ; N=1365]$ agrees or strongly agrees that fathers should have less responsibility for child rearing than mothers. Twenty percent $[\mathrm{n}=155 ; \mathrm{N}=786]$ of Black African males agree or strongly agree fathers should have less responsibility for child rearing than mothers, which is shared by $13 \%[\mathrm{n}=26 ; \mathrm{N}=206]$ of Colored males, $14 \%$ $[n=22 ; N=153]$ of Indian/Asian males, $11 \%[n=24 ; N=218]$ of White males.

\section{Attitudes Towards Raising and Disciplining Children}

These results are from items on views about how to raise children. To each of the items respondents could select one of the following options: strongly agree, agree, neither/nor, disagree, strongly disagree or do not know. The neither/nor, and do not know categories were included in analyses but not reported in these results as they often had few responses.

\section{Children Spoiled by Picking them Up When They Cry}

A little over half $[54 \%, n=737 ; N=1366]$ of the males disagree or strongly disagree that: "Parents will spoil their children by picking them up and comforting them when they cry". About one third of the males [37\%, $n=511 ; \mathrm{N}=1,366]$ agree or strongly agree that picking them up and comforting them when they cry will spoil children.

Forty one percent $[\mathrm{n}=326 ; \mathrm{N}=787]$ of Black African males agree or strongly agree that picking them up and comforting them when they cry will spoil children, which was a view also shared by $31 \%[\mathrm{n}=63 ; \mathrm{N}=206]$ of Colored males, $44 \%$ [ $n=67 ; N=154]$, of Indian/Asian males, and $25 \%$ $[\mathrm{n}=54 ; \mathrm{N}=217]$ of White males. The vast majority [91\%, $\mathrm{n}=1,245 ; \mathrm{N}=1371]$ agrees or strongly agrees that: "Children should be taught to obey their parents at all times".

\section{Children Should Never Be Spanked}

Over half of the males [ $57 \%, \mathrm{n}=770 ; \mathrm{N}=1359]$ disagree or strongly disagree that: "Children should never be spanked when they misbehave" (Table 1). This view was held by $56 \%[\mathrm{n}=440 ; \mathrm{N}=780]$ of Black African males, $58 \%[\mathrm{n}=119$; $\mathrm{N}=205]$ of Colored males, 53\% [n=82; N=154] of Indian/Asian males, and $59 \%[\mathrm{n}=129 ; \mathrm{N}=218]$ of White males. On the other hand over a quarter $[28 \%, n=375$; $\mathrm{N}=1359$ ] of the males agree or strongly agree that children should never be spanked.

\section{Spanking Teaches Right from Wrong}

Consistent with the large number of males who disagree or strongly disagree that children should never be spanked, is a concomitant belief by $61 \%[n=827 ; N=1,361]$ of the males who agree or strongly agree that: "Spanking teaches children right from wrong (Table 2)". Sixty-three percent $[n=490$; 
Table 1. Children should never be spanked when they misbehave.

\begin{tabular}{|c|c|c|c|c|c|c|c|}
\hline & $\mathrm{n}$ & $\begin{array}{r}\text { Strongly Agree } \\
73\end{array}$ & $\begin{array}{r}\text { Agree } \\
159\end{array}$ & $\begin{array}{r}\text { Neither Agree Nor Disagree } \\
108\end{array}$ & $\begin{array}{r}\text { Disagree } \\
334\end{array}$ & $\begin{array}{r}\text { Strongly Disagree } \\
106\end{array}$ & $\begin{array}{r}\text { Total } \\
780\end{array}$ \\
\hline \multirow{2}{*}{ Colored } & $\mathrm{n}$ & 7 & 45 & 34 & 97 & 22 & 205 \\
\hline & $\%$ & $3.4 \%$ & $22.0 \%$ & $16.6 \%$ & $47.3 \%$ & $10.7 \%$ & $100.0 \%$ \\
\hline Indian/Asian & $\%$ & $9.1 \%$ & $20.1 \%$ & 17. $5 \%$ & $46.8 \%$ & $6.5 \%$ & $100.0 \%$ \\
\hline \multirow{2}{*}{ White } & $\mathrm{n}$ & 7 & 37 & 45 & 102 & 27 & 218 \\
\hline & $\%$ & 3. $2 \%$ & $17.0 \%$ & $20.6 \%$ & $46.8 \%$ & $12.4 \%$ & $100.0 \%$ \\
\hline Other & $\mathrm{n}$ & 1 & 1 & 0 & 0 & 0 & 2 \\
\hline
\end{tabular}

Source: 2012 South African Social Attitudes Survey (SASAS), Human Sciences Research Council (HSRC).

Table 2. Spanking teaches children right from wrong.

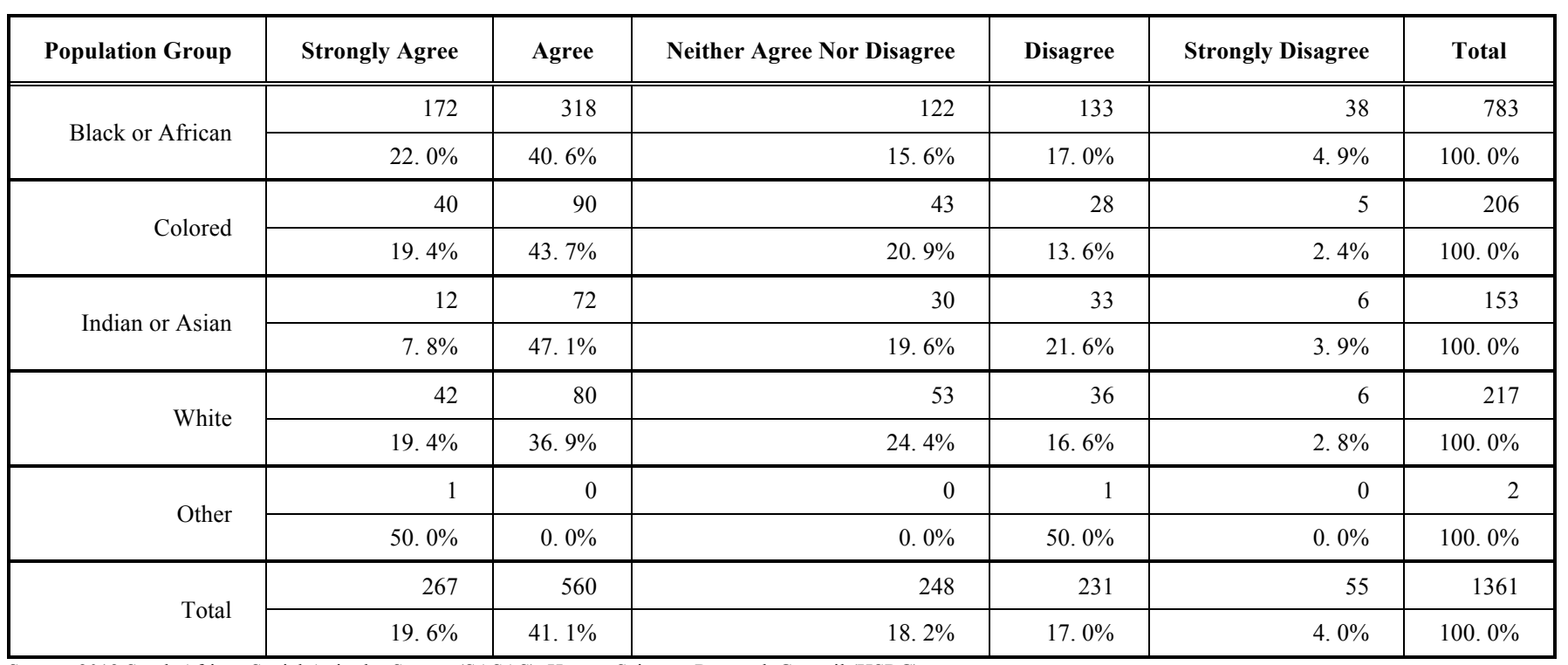

Source: 2012 South African Social Attitudes Survey (SASAS), Human Sciences Research Council (HSRC).

$\mathrm{N}=783$ ] of Black African males agree or strongly agree, "Spanking teaches children right from wrong". This view is shared by $63 \%[n=130 ; N=206]$ of Colored males, $55 \%$ $[\mathrm{n}=84 ; \mathrm{N}=153]$ of Indian/Asian males, and $56 \%[\mathrm{n}=122$; $\mathrm{N}=217]$ of White males. A little less than a quarter [21\%, $\mathrm{n}=286 ; \mathrm{N}=1,361]$ of the males disagree or strongly disagree that spanking teaches children right from wrong.

\section{Last Time Someone Smacked a Child in Your Family}

Respondents were also asked: "When was the last time you or your partner smacked one of the children in your family?" There were seven categories that represented the male's responses. Responses in, "it has happened in the past year", were aggregated and collapsed with three other categories: past 6 months, past month, and past week given the small frequencies per category. The results were that
$25 \%[\mathrm{n}=344 ; \mathrm{N}=1,358]$ of the males indicated children never get smack in their household, $15 \%[\mathrm{n}=206]$ indicated it happened longer than a year ago, 27\% $[n=368 ; N=1,358]$ indicated it has happened in the past year (including either the past 6 months, past month, or the past week). However, $32 \%[n=440]$ of respondents indicated they have no children in the family [house].

Overall when it comes to raising and disciplining their children $64 \%[n=872 ; N=1,364]$ agree or strongly agree that: "When children do wrong it is always better to talk to them then to smack them". Only $15 \%[\mathrm{n}=210 ; \mathrm{N}=1364]$ of males disagree with this view.

\section{DISCUSSION}

In answer to our first question: "What are the attitudes of South African men towards children, childrearing, 
fatherhood and discipline?"According to responses in this survey South African males have a favorable view for children. However, most of them consider watching children growing up as a joy and do not view them as a financial burden, nor restricting their career choices. This is certainly consistent with some studies on expressed views of males about parenthood, particularly youth's aspirations of being a parent $[17,25,26]$. In these studies, aspirations of males for fatherhood mixes with the realities of life and a pessimistic outlook for youth given the impact by absent fathers upon life opportunities [8]. Poverty is also a factor in attitudes towards the responsibilities of having children, participating in childrearing, and absence in the home [14]. This might account for why in our sample, one third of Black African males believe children interfere with parents' freedom, are a financial burden and restrict employment or career choices. About $20 \%$ of Colored males view children as interfering with parent's freedom and restrict employment and career choices. Twenty percent of White males view children as a financial burden and restrict employment and career choices. These views reflect other findings on how necessity and capacity for financial support of children impacts males' attachment to children; the perceived value of having children, and therefore their possible attitude towards participation in childrearing $[25,27,28]$. These racial differences in views are important in understanding the responses to delivery of services, efficacy of interventions, and in policy formation.

In answer to our second question: "Do attitudes of South African men vary by the survey designated racial groups of: Black African, Colored, Asian/Indian, and White?" The evidence that Black African male respondents, in a greater number than the males in other racial groups, viewed children as interfering with parent's freedom, a financial burden, and restricting employment opportunities supports the need for further population studies. Differences by populations have implications for developing population appropriate interventions for strengthening fatherhood and male involvement with families.

Personal experiences in childhood, such as determined by racial group membership for example, are only some of the elements in the multiplicity of factors influencing how males view fatherhood. Morrell represents this complexity in drawing our attention to the greater interface between fathers, fatherhood and masculinity [29]. For example another dimension of fathers' views about children is how they make a contribution towards helping parents later in life. A large majority of males in the sample view adult children as a source of help for the elderly underscoring traditional expectations about family assistance to elders.

We expect males' attitude on decision making about childrearing to inform the interface between views towards fatherhood and masculinity. In general, approximately half of the males in the sample indicate that they share decision making in childrearing with their partner with almost a quarter of the males noting that they mostly make such decisions. Given the concern about the number of males not co-residing with their children, along with the discourse to acknowledge positive contributions other males in the family and community contribute to childrearing as "social fathers", research needs to be broadened to represent an expanded conceptualization of fathering $[8,18]$.

The majority of males express concern for the number of fathers not living with their children in South Africa. Males viewed having a loving relationship with their children as desirous and important. The majority believes that you get high respect for being a father. This is a view that has endured for generations and is connected to African traditions, as well as in aspirations for future fatherhood by boys in spite of their negative experiences from father absence [26, 30]. Moreover, a majority of males believe achieving as a father is best when being married to their children's mother, sharing in child rearing responsibility, and when they feel adequate about their ability to provide for the family.

Males certainly consider these positive views as aspirational, foundational for parental and marital relationships, and favorable for supporting efforts to strengthen the involvement of men in families [31]. However, there is a caveat to males' positive views towards children, childrearing, fatherhood and discipline given the evidence of many not co-residing or supporting families [8]. Involvement of males in fathering connects to a relationship with the mother, the level of participation in childrearing and the ability to provide for the family. Research on nonresident fathers in the United States links success in father connection with children to a multiplicity of factors including the quality of co-parenting relationship mediating paternal involvement $[32,33]$. This is likely true in South Africa.

Views on childrearing and discipline of children are diverse among South African men, which further suggest the need to study population differences. Over one third of Black Africans and Indian/Asian males in the sample view that picking up and comforting children when they cry will spoil them. Approximately, a quarter of Colored and White males in the sample had the same view. Over half of the males in this sample, consistent across racial groups, agree to the use of spanking, as it teaches right from wrong, and teaches children to obey their parents. A modest number of males in this sample no longer believe in traditional ways of raising children, as illustrated by the fact that they do not believe in spanking children, and believe in the "soft" side of parenting like picking up and comforting children. Significantly, many men do not have a chance of practising parental skills, as they are not co-residing with their children [8].

In answer to our third question: "Are there particular trends in the attitudes of South African men that can have implications for fatherhood policy?" The hopeful outcome in this survey is the positive outlook by the South African male respondents towards children, childrearing, fatherhood and discipline. They include the attitudes that being a good father are to be in partnership with the mother, and co-reside with the family. Another trend of concern however, is the perceived greater burden of having children manifested in the attitudes of Black African males in South Africa in contrast to the other racial populations. To a lesser extent, Colored males in the population also perceive this level of burden. Indian/Asian males trend to believe children are less of a general burden in contrast to the other racial 
populations. Overall, there are differences between and trends in the racial populations that warrant further study.

Policy and intervention programs that develop from understanding South African male perspectives perhaps have a better chance to succeed in efforts at strengthening fathers' involvement with their children. The challenge remains structural constraints such as migration patterns, inadequate educational achievement, job skills and work opportunities that reduce achievement of program intervention goals. Further analyses and use of results from the SASAS can provide additional insights into the attitudes of a diverse South African male population towards children, childrearing, fatherhood and discipline.

\section{CONCLUSION}

This particular 2012 South African Survey of Social Attitudes provided a unique opportunity for looking at men's views with questions focused upon attitudes towards children, childrearing, fatherhood and discipline. It also allowed us to capitalize upon a subsample of diverse male respondents within a nationally representative sample of South African households. Although, it is a limitation that sub sample is not a representative sample of males, it is a critical mass of data on males that adds value to research on men. Family and gender roles are changing in South Africa as they are across the globe [5, 9, 34]. This places strain upon adherence to traditional values and practices. The social restructuring in rural and urban family life in contemporary times has implications not only for research but also for family practitioners who provide an array of services to them.

We concur with Hosegood and Madhavan that utilizing existing sources of data from surveys and population cohorts is essential, as well as the need for refining those methods of research [5]. Systematically sampling the attitudes of fathers not co-residing or even connected to their children would include another significant population of males, and no doubt provide greater insight into their perspective on fatherhood, masculinity, and changing male roles in society. Future survey research should develop targeted questions in strategic domains of inquiry with a representative sample of men to refine knowledge and scholarship about men and masculinity.

Men in their attitudes engaged the ideal of fatherhood. Aspirations, expectations, motivation, capacity and efficacy are elements of fatherhood aptly represented in many of the scholarly articles found in Baba: Men and Fatherhood in South Africa [6]. Nonetheless, the traditional role of men has been challenged by the rising rate of high unemployment and numerous other social and economic factors so that a number of men cannot play the traditional role expected of them. It is the men's role outside that of being providers that have suffered most. The fact that some men cannot provide for their families has brought crises to fatherhood in South Africa. In the face of this challenge, there is a more compelling argument that society's view of men's roles towards children, childrearing, fatherhood and discipline must widen to embrace the "social father", that is, kin and significant other males in the community.

Franklin's theory of the "invisibility syndrome" conveys how the dominant public discourses and stereotypes about
Black men in the United States can overshadow the integrity and good deeds of men who are not what others tend to presume solely based upon their membership in a gender group $[35,36]$. Consequently, the negative image of males as "absent fathers" generalizes all males as fathers erroneously, obfuscating the contributions of fathers fulfilling their responsibilities such as co-residing fathers, connected fathers, and the "social father". Some elements of this phenomenon of invisibility manifest in the discourse about men and fathers in South Africa by the efforts to reconceptualize fatherhood. Embedded in this reconceptualization, is an acknowledgement of the good faith effort of men who assume the mantle of fatherhood and are resilient in the role $[18,19]$. Men who get discouraged as a father and disillusioned in their masculine identity will have their attitudes towards children, childrearing, fatherhood, and discipline affected [28, 35, 37]. The major question is how men can fulfill their roles competently in the face of stark structural impediments and prevailing attitudes towards men, fathers and fatherhood. Conceptualization of fatherhood to include the array of males with positive attitudes towards childrearing, and who participate in the nurturing of children independent of biological connections could broaden fatherhood interventions and related policies, as well as it is an important direction for family researchers and practitioners

\section{CONFLICT OF INTEREST}

The authors confirm that this article content has no conflict of interest.

\section{ACKNOWLEDGEMENTS}

This SASAS 2012 family research was funded by a large financial contribution from the South African Department of Science and Technology (DST), as well as a Programme to Support Pro-Poor Development (PSPPD) Phase II Grant (EuropeAid/134258/M/ACT/ZA PSPPD2/ CfP1/2013/47) titled "Family Cohesion, values and strengthening in promoting family well-being in South Africa". The PSPPD is a partnership between The Presidency, Republic of South Africa and The European Union. We are also grateful to the Human Sciences Research Council research staff (data collectors, capturers, supervisors and administrators) and the individuals and their families who participated in the study. The views expressed in this article are the authors' own and do not necessarily represent those of DST, The Presidency or the European Union.

\section{REFERENCES}

[1] Richter L, Chikovore J, Makusha T. The status of fatherhood and fathering in South Africa. Childhood Educ 2010; 86(6): 360-65.

[2] Townsend NW, Madhavan S, Garey AI. Father presence in rural South Africa. Int J of Soc of the Family 2006; 32(2):173-90.

[3] Ramphele, M, Richter, L. Migrancy, family dissolution and fatherhood. In: Richter L, Morrell R, Eds. Baba: Men and fatherhood in South Africa. Cape Town, South Africa: Human Science Research Council 2006; pp. 73-81.

[4] Morrell, R, Richter, L. The fatherhood project: Confronting issues of masculinity and sexuality. Agenda: Empowering women for gender equity 2004; 62(1): 36-44.

[5] Hosegood, V, Madhavan, S. Understanding fatherhood and father involvement in South Africa: Insights from surveys and population cohorts. Fathering 2012; 10(3): 257-73. 
[6] Richter L, Morrell R, Eds. Baba: Men and fatherhood in South Africa. Cape Town, South Africa: Human Sciences Research Council 2006.

[7] Gordon, S, Struwig, J, Roberts, B. Family ties: Blood is thicker than water. HSRC Rev 2013; pp. 17-9.

[8] Holborn, L. Broken families breaking youth. In: Fast Facts. South Afr Inst Race Relat 2011; 5: 2-11.

[9] United Nations Report. Men in families and family policy in a changing world. The Department of Economic and Social Affairs, Division for Social Policy and Development. New York, NY: United Nations 2011.

[10] Hall K, Meintjes, H. Statistics on the number and proportion of children living with parents in South Africa. Children's Institute: University of Cape Town [Online]. 2013 Oct, [cited 2014]. Available from: http://childrencount.ci.org.za/indicator.php?id=1\&I ndicator $=2$

[11] Hall K, Meintjes, H. Statistics on the total number of children living in South Africa. Children's Institute: University of Cape Town [Online]. 2009 Oct, [cited 2014]. Available from: http://childrencount. ci. org. za/indicator. php?id=1\&indicator $=1$

[12] Breckenridge, K. The allure of violence: Men, race and masculinity on the South African goldmines, 1900-950. J South Afr Stud 1998; 24: 669-93.

[13] Morrell, R, Ed. Changing men in Southern Africa. Pietermaritzburg/London: University of Natal Press/Zed Books 2001.

[14] Haour-Knipe, M. Migration, families and men in families. In: United Nations Report: Men in families and family policy in a changing world. The Department of Economic and Social Affairs, Division for Social Policy and Development. New York, NY: United Nations 2011; pp. 125-62.

[15] Moodie, T, Ndatshe, V. Going for gold: Men, mines and migration. Johannesburg, South Africa: Witwaterstrand University Press 1984.

[16] Silberschmidt, M. Women forget that men are the masters': Gender antagonism and socio-economic change in Kisili District, Kenya. Copenhagen, Denmark: Nordiska Afrikainstitutet 1999.

[17] Emmett T, Richter L, Makiwane M, et al. The status of youth report 2003. Johannesburg, South Africa: Umsobomvu Youth Fund 2004.

[18] Madhavan S, Townsend NW, Garey AI. Absent breadwinners: Father-child connections and paternal support in rural South Africa. J South Afr Stud 2008; 34 (3): 647-63.

[19] Ratele K, Shefer T, Clowes L. Talking South African fathers: a critical examination of men's constructions and experiences of fatherhood and fatherlessness. South Afr J Psycol 2012; 42 (4): 553-63.

[20] Wilson F. Understanding the past to reshape the future: Problems of South Africa's transition. In: Davis, P, Thomas, M, Eds. The economic future in historical perspective. Oxford, United Kingdom: Oxford University Press 2003; pp. 297-313.

[21] Moodie D. Black migrant labourers and the vicissitudes of male desire. In: Morrell, R, Ed. Changing men in Southern Africa. Pietermaritzburg/London: University of Natal Press/Zed Books 2001; pp. 297-315.
[22] Miller S, Sambell K. What do parents feel they need? Implications of parents' perspectives for the facilitation of parenting programmes. Child Soc 2003; 17(1): 32-44.

[23] Lamb ME, Ed. The role of the father in child development. Hoboken, NJ: John Wiley \& Sons Inc. 2010.

[24] Liang CTH, Salcedo J, Miller HA. Perceived racism, masculinity ideologies, and gender role conflict among Latino men. Psychol Men Masc 2011; 12(3): 201-15

[25] Rabe M. Being a father in a man's world: the experience of goldmine workers. In: Richter, L, Morrell, R, Eds. Baba: Men and fatherhood in South Africa. Cape Town, South Africa: Human Sciences Research Council 2006; pp. 250-64.

[26] Spjeldnaes IO, Moland KM, Harris J, Sam DL. "Being man enough": Fatherhood experiences and expectations among teenage boys in South Africa. Fathering 2011; 9(1): 3-21.

[27] Khunou G. Fathers don't stand a chance: experiences of custody, access, and maintenance. In: Richter L, Morrell R, Eds. Baba: Men and fatherhood in South Africa. Cape Town, South Africa: Human Sciences Research Council 2006; pp. 265-77.

[28] Hunter M. Fathers without amandla: Zulu-speaking men and fatherhood. In: Richter L, Morrell R, Eds. Baba: Men and fatherhood in South Africa. Cape Town, South Africa: Human Sciences Research Council 2006; pp. 99-107.

[29] Morrell R. Fathers, fatherhood and masculinity in South Africa. In Richter, L, Morrell, R, Eds. Baba: Men and fatherhood in South Africa. Cape Town, South Africa: Human Sciences Research Council 2006; pp. 99-107.

[30] Mkhize N. African traditions and the social, economic and moral dimensions of fatherhood. In: Richter L, Morrell R, Eds. Baba: Men and fatherhood in South Africa. Cape Town, South Africa: Human Sciences Research Council 2006; pp. 183-98.

[31] Peacock P, Botha M. The new gender platforms and fatherhood. In Richter L, Morrell R, Eds. Baba: Men and fatherhood in South Africa. Cape Town, South Africa: Human Science Research Council 2006; pp. 281-92.

[32] Doherty WJ, Kouneski EF, Erickson MF. Responsible fathering: An overview and conceptual framework. J Marriage Fam 1998; 60: 277-92.

[33] Coates, EE, Phares, V. Predictors of paternal involvement among non-residential Black fathers from low income neighborhoods. Psychol Men Masc 2014; 15(2): 138-51.

[34] Hosking A. Men, work and parenting. In: Richter L, Morrell R, Eds. Baba: Men and fatherhood in South Africa. Cape Town, South Africa: Human Sciences Research Council 2006; pp. 216-25.

[35] Franklin AJ. From brotherhood to manhood: How Black men rescue their relationships and dreams from the invisibility syndrome. New York, NY: John Wiley 2004.

[36] Franklin AJ. Another side of invisibility: Present and responsible Black fathers. In: Oren CZ, Oren DC, Eds. Counseling fathers: Practical, theoretical, and cultural perspectives. New York, NY: Routledge/Taylor \& Francis Group 2009; pp. 121-40.

[37] Franklin AJ, Boyd-Franklin N. Invisibility syndrome: A clinical model of the effects of racism on African American males. Am J Orthopsychiatry 2000; 70(1): 33-41. 